\title{
Development of personal qualities of gifted students as the result of the implementation of individual educational routes
}

\author{
Alena Kremneva ${ }^{1}$, Marina Gumerova $^{1}$, Irina Zakharova $^{2 *}$, Lily Sadykova ${ }^{3}$, Azat Rafikov $^{4}$, \\ and Rustam Malikov ${ }^{1}$ \\ ${ }^{1}$ Department of Pedagogy, Naberezhnye Chelny State Pedagogical University, Naberezhnye Chelny, \\ Russia \\ ${ }^{2}$ Department of theory and Methods of primary and preschool education, Naberezhnye Chelny State \\ Pedagogical University, Naberezhnye Chelny, Russia \\ ${ }^{3}$ Department of Psychological, Pedagogical and Special Defectological Education, Naberezhnye \\ Chelny State Pedagogical University, Naberezhnye Chelny, Russia \\ ${ }^{4}$ Department of History and Methods of Its Teaching, Naberezhnye Chelny State Pedagogical \\ University, Naberezhnye Chelny, Russia
}

\begin{abstract}
The need to create favorable conditions in schools to support gifted and talented students is due to the social order and humanistic paradigm of modern education. This article deals with the problem of developing personal qualities of students in the framework of pedagogical support for students with signs of giftedness in the modern school. The article reveals the results of the study of personal development of students accompanied by teachers in the process of designing and implementing individual educational routes at the main stage of general education. The leading method of studying this problem is the analysis of the results of the survey of teachers and schoolchildren in order to determine changes in the manifestation and development of personal qualities of students with signs of giftedness, accompanied by teachers, in the process of implementing their individual educational path using the model of the educational route developed by the authors of the article. The summary of the research presented in the article is the development and testing the structuralfunctional model of individual educational route for students with signs of giftedness, the use of which contributes to the manifestation and development of personal qualities of students required for the development of their potential and achieving educational outcomes. The materials of the article are of practical value for teachers when planning individual work at school.
\end{abstract}

\section{Introduction}

In modern pedagogical practice, the development and pedagogical support of gifted children is the topic and the subject of numerous discussions. Early identification, support

\footnotetext{
* Corresponding author: zaharova-i@mail.ru
} 
and development of the potential of gifted children remain one of the main directions of improving the modern educational system.

The analysis of psychological and pedagogical literature allowed us to determine that giftedness is a phenomenon that is expressed in the person's ability of achieving goals, high or outstanding results in a particular activity; the manifestation of a peculiar combination of: personal qualities, motivation, creativity and interest for studies, determined by the inclinations of the individual. All components can manifest themselves to varying degrees, with the conditionality of the system, internal (individual) prerequisites of the personality as well as external factors [1], [2].

McClain and Pfeiffer provide a broad definition of the gifted that covers these various aspects and attributes, describing this population as those who "exhibit outstanding intellectual ability, or promise, and are capable of extraordinary performance and accomplishment". Peterson describes gifted individuals

as those with exceptionally high ability, "regardless of academic performance". Thus, Peterson is arguing that a framework for this definition should be inclusive of both those who have remarkable achievements, as well as those with the capacity to do so [3].

Considering this phenomenon, we agree with the remark of the authors of "Working Concept of Giftedness" that in pedagogical practice the term "gifted child" should be replaced by the term "child with signs of giftedness" [1, p. 12].

From the pedagogical position, as a rule, attention is focused on giftedness associated with the successful educational activities of schoolchildren, aimed at acquiring knowledge and developing competencies.

\section{Materials and methods}

The results of numerous psychological and pedagogical studies indicate that the role of personal qualities in the development of giftedness is great. The potential of a child, according to Leites N., depends not only on mental abilities, but also on the qualities of his/her personality. Creative efforts and achievements are the result of the manifestation of not only the mindset, but also of certain character traits, the volitional sphere. Much in the formation of the intellect of children (who are ahead of their age) depends on value attitudes [4].

Also, Cox C. found out that great people became famous not only for their achievements, but also for their personal characteristics. The scientist focused on three properties: the constancy of motives and efforts, confidence in their abilities, strength of character [5].

Analysis of foreign publications on our topic has revealed that in western culture intelligence is conceptualized as dynamic, 'as developing over time with appropriately scaffolded opportunities to learn' [6].

Some aspects considered in our study are also the object of close attention of the international scientific community. Monks F., Heller K., Passov H. state that educational programs for the gifted should be based upon the needs of the individual learners rather than upon making up for the program deficits in a curriculum for the non-gifted. There is a resultant difference between enriching or accelerating an inadequate curriculum and designing and adequate and appropriate curriculum for use in the first place [7].

So, considering the individuality of schoolchildren while organizing the effective education of gifted children, in our opinion, is feasible by means of designing and implementation of individual educational route of learning, which is movement in the educational space created for a particular gifted child [8].

In foreign research woks it is said that gifted students, like other students, benefit from the opportunity when they can express themselves through their work, and "providing 
students with choices within a curriculum provides a unique basis for self-assessment and will likely result in increased motivation and positive self-concept [9].

The analysis made it possible to make sure that one of the most important factors influencing the development of the personality of a gifted student, as described by Russian and foreign scientists in terms of teaching children with signs of giftedness, is the factor of development of students' personal qualities.

Our approach to the implementation of pedagogical support by means of educational routes for gifted students is based on the research works of Alexandrova, Lekomtseva, Zolotareva, Kunash, [10], [11], 12]. To organize effective pedagogical support, it is necessary to develop individual educational routes. For this purpose and to provide teachers with methodological tools, we suppose, a model of a mono-subject educational route should be designed as a means for pedagogical support of students with signs of giftedness. In this regard, the objectives of the research were formulated as follows:

1. To reveal the opinions of students with signs of giftedness and teachers for further considering their opinions and demands when developing the form and structure of the model of an individual educational route (the first stage of this research).

2. To study the manifestation and dynamics of the development of personal qualities of students in the process of implementing their routes (the second stage of the research).

Thus, the experimental work involved 72 teenagers with signs of giftedness (secondary school students, grades 5-9) and their teachers (31 teachers of educational institutions).

The study made it possible to design a model of a mono-school subject educational route as a tool for pedagogical support of students with signs of giftedness, the model based on an analysis of the opinions and preferences of students and teachers about the form and structural components of an individual educational route (IER) [13].

The IER model developed by us is characterized by the interconnectedness of three blocks (motivational-organizational block, procedural-technological block and effectivereflexive block), which include a number of interrelated structural components and sequential stages of work in the system of designing and implementing an individual route:

- target component (defining a strategy - directions of movement, defining motives and needs, setting an educational goal, defining objectives, formulating planned results and achievements, defining the time period for implementing IER);

- content and procedure components (selection of subject content, selection of forms, types, methods of work, forms of presentation of results, selection of the level of complexity of tasks of educational material, development of an educational program: determination of subject content modules and technological tools, development of tasks for modules, determination of information resources and control materials, determination and observance of conditions ensuring the achievement of the goal, involving parents in organizing the conditions of a variable educational environment, implementation of tasks, presentation of results);

- the result-controlling component (defining the forms of control and presentation of results, defining the schedule for fulfilling tasks, exercising control and self-control, completing a portfolio of achievements);

- reflexive-corrective component (defining the criteria for the effectiveness of the IER implementation, self-reflection activity, self-assessment, route correction).

At the second stage of the research, in the course of experimental work, we analyzed the development of personal qualities of students with signs of giftedness in the process of pedagogical support by means of designing and implementation of their routes with the help of the model of a single-subject individual educational route we had developed.

To assess the students'personal qualities and their development we used the following methods and techniques: 
- methodology of Ilyin E. and Feshchenko E. "Questionnaire for assessing your perseverance " [14];

- Obozov's methodology "Self-assessment of willpower" [15];

- Rean's questionnaire "Motivation for success and fear of failure" [16];

- a questionnaire developed by us for students with signs of giftedness and their teachers-mentors;

- interview with students and their teachers-mentors based on the author's questionnaires.

\section{Results and discussion}

The analysis of psychological and pedagogical literature points to the fact that the most important criterion for a child's development is the presence of such qualities as: will to achieve goals, willpower, perseverance, diligence, and intellectual curiosity, which are necessary for the development of personal potential. In the course of this work, it was decided to monitor the dynamics of the manifestation and the development of the mentioned above personal qualities of adolescents with signs of giftedness as the result of their implementation of educational routes based on the IER model we proposed.

At the beginning and at the end of the designing and implementation of individual educational routes within the framework of the experiment, students with signs of giftedness and their teachers, who took part in the experimental work, noted the students'qualities that were just shown and were developing. An analysis of the answers of teachers and adolescents about the presence and the development of the personal qualities of students is presented in tables 1,2 .

At the ascertaining stage of the experimental work, the subjects were asked about the presence in the students'character of such qualities as intellectual curiosity, purposefulness (will to achieve goals), willpower, perseverance, diligence, and laziness in the course of planning and organizing their own educational activities (Table 1).

It was found that $87.5 \%$ of the students noted intellectual curiosity as a quality they noted while doing their educational activities, which indicates the fact that the tested adolescents have a cognitive interest which is a marked characteristic of representatives of the category of students under consideration. Purposefulness in their educational activities was noted by $65.2 \%$ of students, perseverance - in the answers of $66 \%$ of the students. At the same time, $73.6 \%$ of the tested adolescents noted diligence as a trait that shows itself and develops during their educational work. 
Table 1. Indicators of the presence of personal qualities according to the results of a questionnaire survey of students with signs of giftedness and their teachers.

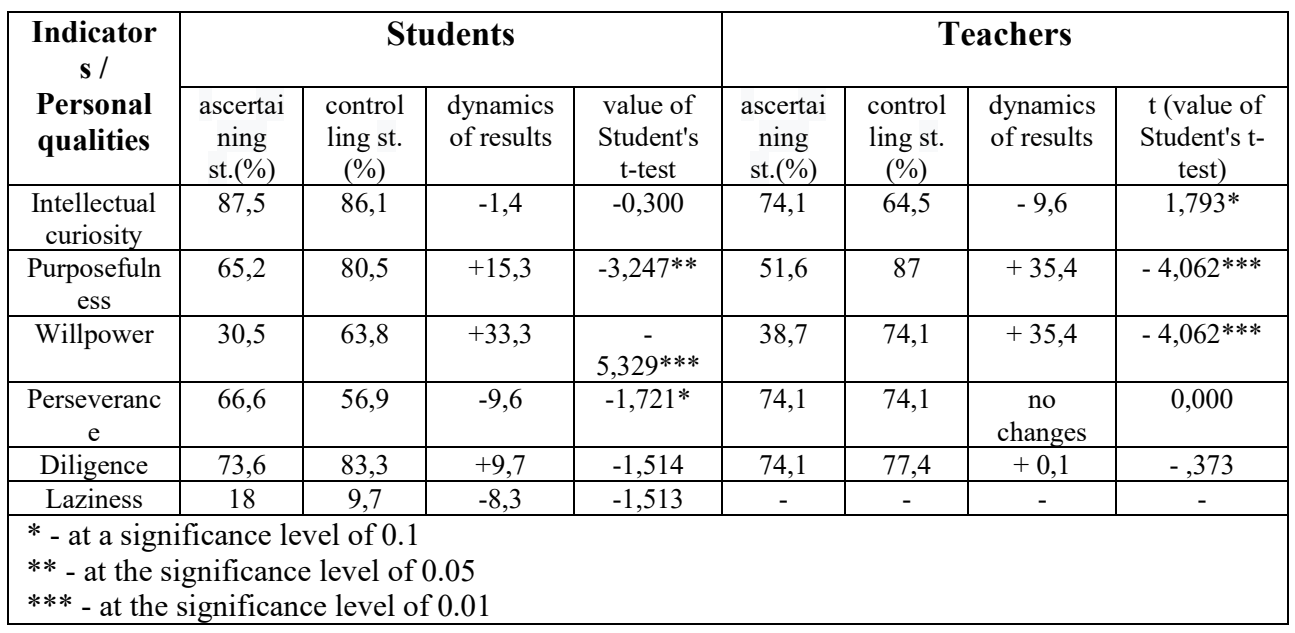

Analysis of the respondents' answers at the ascertaining stage according to the results of work on individual routes on the basis of the proposed model allowed us to conclude that there is a positive dynamics of indicators of such quality as "purposefulness -will to achieve goals" (by $15.3 \%$ among adolescents' answers and by $35.4 \%$ among teachers' answers). The number of respondents who noted 'intellectual curiosity' in the questionnaire, as the quality the students showed in educational activities, decreased (from $87.5 \%$ to $86.1 \%$ according to the answers of students and from $74.1 \%$ to $54.5 \%$ according to the indicators of teachers' answers).

Additional individual interviews with adolescents and teachers made it possible to clarify the depth of understanding the interpretation of the concept "intellectual curiosity". So, according to the mutual opinion of students and their teachers, "curiosity prompts to begin ... the study of subjects, things that interested them, and, gradually, plunging into the issue, studying, working on topics, purposefulness appears, movement towards the goal begins."

The analysis of the results of a questionnaire survey among teachers of teenagers with signs of giftedness showed that the number of respondents noting the development of students' willpower during the experiment increased (by 35.4\%). This positive trend is also observed in the answers of students, which is confirmed by an increase of $33.3 \%$ in the number of the observed students indicating the presence (development) of volitional qualities in the character of adolescents (an increase from $30.5 \%$ to $63.8 \%$ of answers).

We consider the fact worth mentioning that only $18 \%$ of the teenagers we surveyed with signs of giftedness at the ascertaining stage of work indicated "laziness" as a quality that is noticed whilst students' educational activities. Moreover, at the end of the experiment, upon completion by the students' implementation of their routes, only $9.7 \%$ of the students' answers pointed to the presence of laziness in the process of their learning activities. It should be noted that none of the teachers $(0 \%)$ indicated this quality in the spectrum of qualities of their pupils either at the beginning of the organization of pedagogical support through the design and implementation of individual routes, or at the control stage of the experiment, as the result of work.

To analyze the differences in the indicators for the answers to the questionnaires at the beginning and at the end of the experimental work for dependent samples of adolescents and dependent samples of teachers, the criterion of Student's $t$ - test was used. Testing the null hypothesis on the absence of differences in indicators in the responses of adolescents at 
the stages of the ascertaining and control experiment and on the absence of differences in indicators in the responses of teachers on the scales of " purposefulness (will to achieve goals)", "willpower", "intellectual curiosity", "perseverance", "diligence", we calculated the values of Student's $t$-criterion and the level of significance - $p$.

The values of the criterion $(t)$ for dependent samples of adolescents and dependent samples of teachers (based on the results of the analysis of answers to questionnaires) are presented in Table 1.

Having analyzed the data we can say that the statistical hypothesis about the equality of the values of the indicators of adolescents on the scales of the variables "purposefulness (will to achieve goals)", "willpower", " perseverance " is rejected, the alternative hypothesis about the presence of differences in the indicators of the considered signs is accepted, since the value of the $t$ - criterion fell into the zone of significance at the level $\leq 0.001$ (on the scales of the variables " purposefulness (will to achieve goals)", "willpower") and at the level of $\mathrm{p} \leq 0.1$ (on the scale " perseverance "). According to the results of the questionnaire survey of students there were no significant changes in the testimony of adolescents on the scales of the variables "intellectual curiosity" and "diligence" at the ascertaining or control stages of the experiment. We conclude that the indicators of adolescents' answers about the development of personal qualities (will to achieve goals and willpower) as a result of designing and implementing individual routes on the base of our model increased statistically significantly. The indicators of students' answers about the industriousness and intellectual curiosity during the experimental work, according to the results of the questionnaire, did not change. The indicators of perseverance (according to the results of the analysis of children's answers to the questionnaire) decreased at the level of $p \leq 0.1$.

Also, according to the results of testing the null hypothesis about the equality of the values of the indicators of teachers on the scales of the variables "purposefulness (will to achieve goals)", "willpower", "intellectual curiosity" at the beginning and at the end of the experimental work, the alternative hypothesis about the presence of differences in the indicators of the considered characteristics of students in the teachers' opinion is accepted, since the value of the $t$ - criterion fell into the zone of significance at the level of $\mathrm{p} \leq 0.001$ (on the scales of the variables "purposefulness", "willpower") and at the level of $p \leq 0.1$ (on the scale "curiosity"). No significant changes in the testimony of teachers on the scales of variables "persistence" and "diligence" were found at the ascertaining and control stages of the experiment according to the results of the questionnaire survey of teachers.

Thus, we can assert about the positive dynamics of the development of personal qualities (purposefulness and willpower) after experimental work on accompanying adolescents by means of designing and implementation of individual routes based on the model we have developed (statistically reliable). Analysis of the teachers' answers allow us to conclude that there were no significant changes in the indicators of the development of perseverance and diligence of students by the end of the experimental work, which can be explained by the presence of such students' qualities already at the ascertaining stage of the experiment, which was established during the questionnaire survey (Table 1).

Let us consider the indicators of students' willpower that we got at the result of their self-assessment according to the questionnaire "Self-assessment of the will", indicated in table 2 . 
Table 2. Indicators of personal qualities: willpower, perseverance, motivation for success of observed students with signs of giftedness according to questionnaires (methodology of Ilyin E. and Feshchenko E. "Questionnaire for assessing your perseverance, Obozov's methodology "Selfassessment of willpower", Rean's questionnaire "Motivation for success and fear of failure").

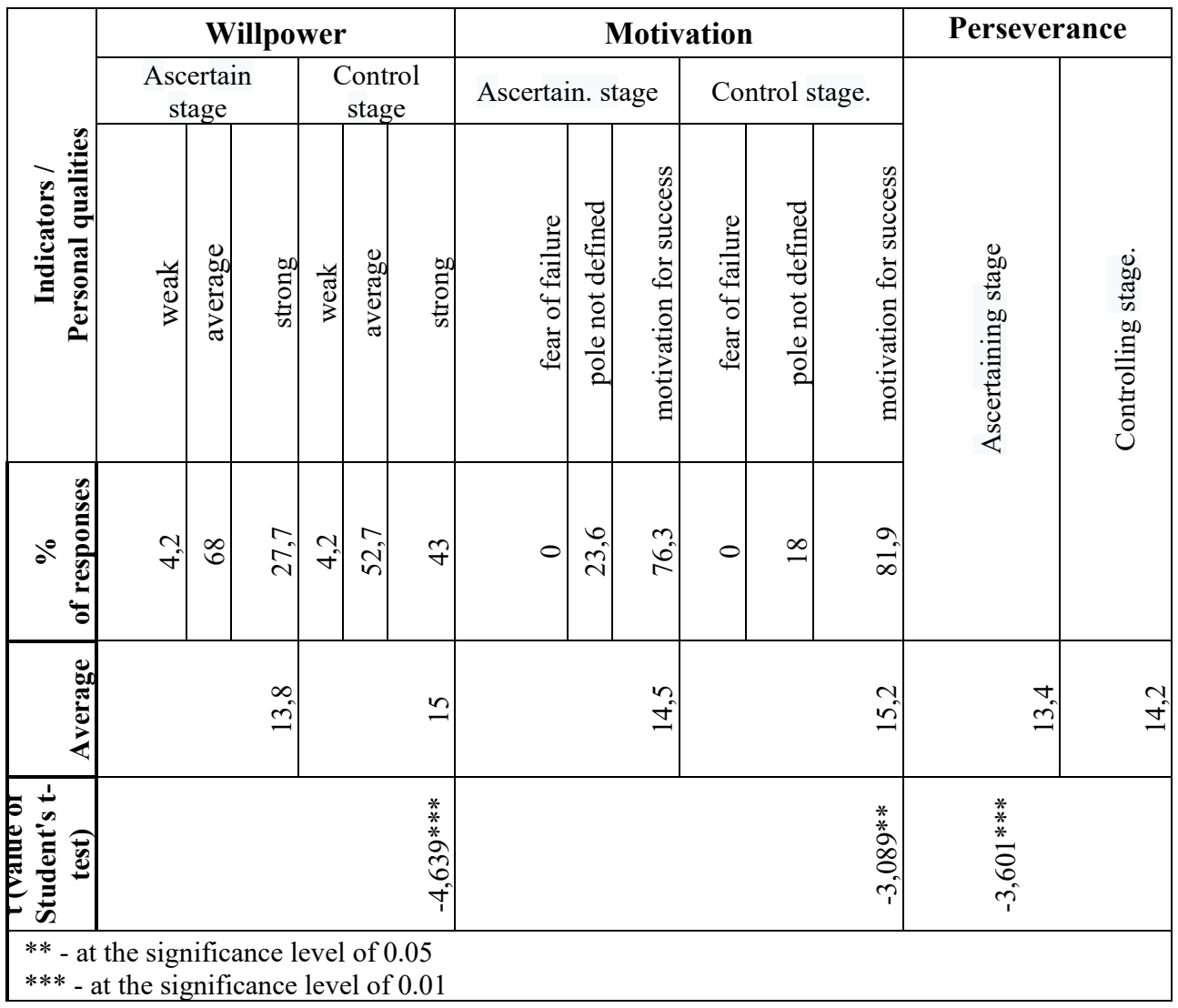

At the ascertaining stage, it was revealed that $4.2 \%$ of students had scores $\leq 7$, which is an indicator (according to the methodology described by Obozov N.) of weak willpower. It should be noted that this indicator has not changed (that, in our opinion, indicates the duration and complexity of the process of developing volitional qualities). However, at the end of the experiment, the number of students who scored the number of points corresponding to the indicators of strong will (15-20 points on the questionnaire) increased from $27.7 \%$ to $43 \%$.

In order to check the significance of the results obtained, the methods of mathematical statistics were used (a computer program for processing statistical data SPSS Statistics). To calculate the differences in indicators in the responses of adolescents at the beginning and at the end of the experimental work, the Student's t test was chosen for dependent samples (the empirical value of the criterion $(t)$ is presented in Table 2).

The null statistical hypothesis of the absence of differences is rejected, $p$-the significance level on the scales of the variables "willpower", "motivation", " perseverance" (the result according to questionnaires) is less than 0.05 , that indicates significant differences in the level of expression of the considered signs of adolescents, growth indicators of willpower, perseverance, motivation for success as a result of designing and implementation of educational activities based on the model of the individual route. 
Interpreting the obtained data according to the questionnaire made it possible to identify the percentage of students who are diagnosed with motivation for success and whose motivational pole is not clearly expressed. It should be noted that of the total number of the observed adolescents with signs of giftedness, none $(0 \%)$ was diagnosed with motivation to fail (fear of failure) either at the ascertaining or at the control stage of the experimental work. We associate this indicator with the fact that the observed adolescents are students with signs of mental and academic types of giftedness, successful in learning activities in several or one subject and / or having outstanding results (or capable of achieving them) in academic process. According to the results of students' educational work, accompanied by their teachers using the model of the individual educational route, the number of adolescents who scored points indicating that the pole of motivation was not expressed, decreased due to an increase in the percentage of students (by 5.6\%) with motivation for success (from $76.3 \%$ up to $81.9 \%$ ).

Testing the degree of perseverance of the dolescents according to the questionnaire developed by Ilyin E. and Feshchenko E., presupposed the calculation of points (one point for the answers "yes" and "no", according to the positions set in the methodology). The maximum possible number of points is 18 points, the more points the subject scored, the higher level of his perseverance is. We calculated the average value of the indicators of the studied group of students at the initial stage of the experiment and at the end of the work. According to the results of the study, an increase in the average score of students' answers from 13.4 to 14.2 was revealed (see Table 2).

We cannot but mention the fact that as a result of the questionnaire survey (see Table 1), the number of adolescents' answers (their own opinion) indicating the manifestation of perseverance in their activities decreased by $9.6 \%$ (in contrast to a significant increase in indicators on the scale "personal quality - willpower"), whereas the subjective responses of teachers indicate the absence of significant changes in relation to students' demonstration of perseverance during the experiment.

We had a conversation with students with signs of giftedness and their teachers on the topic of their understanding the essence of qualities "willpower" and "perseverance". In the teachers' answers, there were such definitions of the concept of "willpower" as "a broad concept that includes persistence, the quality that allows a person to continue to act, overcoming difficulties and obstacles." Perseverance, according to teachers, is "a quality of a person, which presupposes striving for a personal goal, which sometimes may not be planned, sometimes an unconscious one...".

The questions we asked teenagers in personal conversations, "Is there a difference between the willpower and perseverance, in your opinion?" and "What is" willpower "and" perseverance "?" allowed them to think about their own ideas about these personal qualities, which are necessary in their educational activities, and helped us to understand and accumulate the range of their opinions, ideas about the essence of these personal qualities. So, willpower is: "a quality that allows you to achieve your goal", "shows itself when a person needs to continue to work, adhere to planned actions, keeping himself from other, distracting things", "a general character trait which is necessary to achieve the goals set by a person", "an effort that helps you, forces you to continue your work", "necessary to complete the planned, the basis of perseverance." Perseverance, according to the interviewed adolescents, manifests itself "when you need to finish something, prove, insist ...", "when you want to insist on your own, achieve what you want", perseverance is "persistence in your actions and aspirations", "quality necessary for achieving a certain goal "," a quality that makes you go forward, despite the opinions of others and failure." 


\section{Conclusion}

Summarizing the students' answers, we conclude that for the observed adolescents with signs of giftedness and their teachers, the presence, manifestation in character and the development of willpower is an essential, necessary component of successful progress towards the desired goals, the implementation of serious, responsible work, overcoming difficulties. The analysis of the answers to questionnaires for students and teachers unambiguously shows the presence of volitional qualities in characters of the gifted adolescents and an increase in the number of students with strong willpower during the experiment. Also, interpreting the answers of the subjects, we note that perseverance for them is one of the necessary personality traits, allowing them to achieve what they want, showing persistence and tenacity. It should be noted that the average score of answers is 13.4 out of 18 possible (objective assessment according to the questionnaire of Ilyin E. and Feshchenko E.) at the ascertaining stage and the average score (14.2) at the control stage (the dynamics of indicators is statistically significant) may indicate the development of this quality in the personality of students who implement individual educational routes.

The manifestation of perseverance in the activities of the observed students with signs of giftedness was necessary for them to achieve results. Adolescents emphasize the need to have and develop willpower to concentrate efforts in achieving their goals.

Considering the results of the analysis of data on the development of students 'personal qualities in the course of experimental work, we conclude that the design of individual educational routes based on the IER framework model developed by us contributes to the manifestation and growth of students' personal qualities necessary for the development of their academic and creative potential as well as achievement desirable educational outcomes.

\section{References}

1. D. Bogoyavlenskaya (ed.), Working concept of giftedness, 2-nd edition., amended. Moscow (2003).

2. I. Isaeva, Technology of Designing Individual Educational Routes: a tutorial. Magnitogorsk, Magnitogorsk Publ. state tech. un-ty named after G. I. Nosov (2015).

3. K. Kennedy, J. Farley, Counseling gifted students: School-based considerations and strategies. International Electronic Journal of Elementary Education, 10(3), 361-367 (2018).

4. S. Lezina, Study of the Role of Personal Factors in the Development of Giftedness (primary schoolchildren and adolescents): dis. ... candidate of psychological sciences, Moscow, 27 (2001).

5. D. Matthews, Book Review: Mindset: The New Psychology of Success, by Dweck, C. S. (2006), Gifted Children, 1(2), Article 7, 66 (2007).

6. A. Kurt Heller et al. (ed.). International handbook of giftedness and talent, 2. ed. (Rev. repr.). Amsterdam [etc.], Elsevier, XV, 11 (2002).

7. V. Romanov, Individual Educational Route of a Student as a Condition for the Implementation of FGOS when Working with Children with Special Educational Needs [Electronic resource]: Psychological and pedagogical support of gifted children: collection of articles on the materials of the scientific-practical conference, 24-36 (2017). URL: https://elibrary.ru/item.asp?id=32376431

8. A. N. Rinn, J. A. Plucker, V.B. Stocking, Fostering Gifted Students'Affective Development: A Look at the Impact of Academic Self-Concept. TEACHING 
Exceptional Children Plus, 6(4), 32 (2010). Article URL

https://files.eric.ed.gov/fulltext/EJ907033.pdf

9. E.A. Aleksandrova, Pedagogical Support of High School Students in the Development and Implementation of Individual Educational Trajectories: dis. ... Dr. ped. Sciences. Tyumen, 7 (2006).

10. A.V. Zolotareva, E.N. Lekomtseva, A.L. Pikin, Tutor support for a gifted child: textbook for undergraduate and graduate programs. 2nd ed., Rev. and additional. Moscow, Yurayt (2018).

11. M. Kunash, Individual Educational Route of a Student: methodical constructor, models, analysis. Volgograd, Teacher (2013).

12. A. Kremneva, Designing Models of an Individual Educational Route for Students with Signs of Giftedness, Science and school, 4, 205-210 (2019).

13. A. Gretsov, Get to Know Yourself: psychological tests for adolescents, $\mathrm{SPb}$. and others: St. Petersburg, Peter Press, 205 (2006).

14. E P. Ilyin, Psychology of Wil, 2nd ed, St. Petersburg, Peter, (2009).

15. S. D. Nekrasov, Personal characteristics: recommendations for educational practice for students studying in the direction of "Psychology" (bachelor's degree). Krasnodar: Kuban State University, 49-51 (2018).

16. A. Rean, Psychology and Psychodiagnostics of Personality: Theory, Methods, Research., Workshop: the arsenal of a practical psychologist, St. Petersburg, PrimeEvroznak (2006). 